\title{
Yükseköğretim Kurumlarında Yönetici Seçiminde Oy Kararını Etkileyen Kriterlerin Önem Düzeyinin Bulanık AHP Yöntemiyle Belirlenmesi
}

\author{
V. Alpagut YAVUZ*
}

\begin{abstract}
$\ddot{O} Z$
Ülkemizin ekonomik ve sosyal gelişiminde önemli misyon üstlenen devlet üniversitelerinin gelişmelerinde en önemli rolü yetki ve sorumluluklarıla en üst makamda rektörler ve onların yetkisinde oluşturulan yönetim kademeleri üstlenmektedir. Her dört yllda bir üniversitelerde önemli bir gündem konusu olan rektör seçim süreci beraberinde farklı tartışmaları da gündeme getirmis ve sonuçta 2016 yıl Ekim ayında yapılan yasal düzenlemeyle kaldırılmıştır. Oy verenler açısından bu sürecin nasıl bir karar mekanizması içerdiği ampirik açıdan ele alınmamış bir konudur. Bu çalı̧̧mada yüksekögretim kurumlarında dekan, bölüm başkanı gibi yönetici atamalarında isteğe bağll uygulanabilen seçim yöntemi ve önerilecek yeni yöntemlere ışı tutması açısından, devlet üniversitelerinde rektör aday belirleme seçimlerinde oy kullanan ögretim üyelerinin oy kararını verirken hangi kriterleri dikkate aldıkları bir uygulama araştırmasıyla tespit edilmeye çalışılmış ve belirlenen kriterlerin oy kararındaki ăgırlıkları iki farklı metotla Bulanık Analitik Hiyerarşi Prosesi (BAHP) yöntemi kullanılarak hesaplanmıştır. Daha sonra kriterlerin ögretim üyesi unvanlarına göre ne düzeyde değerlendirildiği incelenerek sonuçlar karşılaştırllmuştır. Örneklemden elde edilen sonuçlara göre unvanlar düzeyinde kriter önem sırasının değişmediği tespit edilmiş, fakat kriter önem düzeylerinin unvanlara göre farklılaştığı saptanmıştır.
\end{abstract}

Anahtar Kelimeler: Rektör Seçim Süreci, Bulanık Analitik Hiyerarşi Prosesi, Oy Verme Kararl

JEL Sinıflandirmasi: C02, C44, D72, D81

\section{Determination of the Importance of Criteria Effecting Voting Decision in Management Election in Higher Education Institutions Using Fuzzy AHP}

\begin{abstract}
Rectors and the management teams have the most important role with their authority and responsibilities in the development of public universities which have an important mission in the economic and social development of our country. The process of rector elections once in every four year became an important topic on universities' agenda that caused various discussions. As a result of these discussions rector elections are no longer to be held due to the law that has been changed on October 2016. This process has not been studied empirically in terms of the kind of decision mechanisms involved in the voters' perspective. In this study in order to shed a light on management election process taking place optionally in higher education institutions for dean and chairperson positions and new election system proposals, an empirical research is conducted in order to determine the criteria taken into consideration by faculty members for their voting decisions in the candidate rector elections. For this purpose, the preference of the criteria effecting the voting decision was calculated using Fuzzy AHP method with two different approaches. Next, the evaluations of the criteria in terms of the faculty members' academic titles are investigated and compared to each other. According to the results obtained from the sample, it is determined that the rank order of criteria
\end{abstract}

\footnotetext{
*Yrd.Doç.Dr., Mustafa Kemal Üniversitesi, İktisadi ve İdari Bilimler Fakültesi, İşletme Bölümü. vyavuz@mku.edu.tr
} 
remains the same in terms of all academic titles; however, preference value of the criteria differs across titles.

Key Words: Rector Candidate Selection Process, Fuzzy AHP, Voting Decision

JEL Classification: C02, C44, D72, D81

\section{GíRiş}

Türkiye'de devlet üniversiteleri dört y1llık süreler için atanan Rektör ve rektörün belirlediği yönetim kadrolarıyla yönetilmektedir. Geniş yetki ve sorumluluklarıyla bu yönetimler, üniversitelerin performansında, gelişmelerinde ve oluşan akademik kültürde büyük söz sahibi olmaktadır. Ülkelerin sosyal ve ekonomik anlamda gelişiminde üstlendikleri misyon gereği üniversitelerden beklentiler giderek artmıştır. Günümüzde üniversitelerde üretilen bilgi ve teknoloji sadece akademik açıdan değil, büyük ölçüde toplum ve reel ekonomi için somut faydaları ile de değerlendirilmektedir. $\mathrm{Bu}$ gelişmeler dünya genelinde üniversitelerin piyasa koşullarında rekabet eden özel şirketler gibi yönetilerek verimlilik ve etkinliğin yükseltilmesi odağına sahip olması gerektiğini gündeme getirmiştir (Erdoğmuş, 2014, s.45).

Dünyada üniversitelere yönelik rekabetçi bakış açısı ülkemizde de üniversitelerden beklentileri ihtiyaçlara göre farklılaştırmaya başlamıştır. Bugün artık üniversiteler sadece yaptıkları akademik yayınların ve araştırmaların sayıları düzeyinde değil, bu çalışmaların toplum ve ekonomiye sağladıkları katkılar düzeyinde değerlendirilmektedir. Bu amaçla TÜBİTAK tarafindan oluşturulan Girişimci ve Yenilikçi Üniversite Endeksi her yıl üniversitelerin girişimcilik ve yenilikçilik performansına göre konumlarının belirlenmesinde kullanılmaktadır. $\mathrm{Bu}$ gelişmeler üniversite üst yönetimlerinin ve özellikle rektörlerin performanslarının; kurumlarının yarattığı katma değer yönündeki başarılarıyla da değerlendirilmesini gündeme getirmektedir. $\mathrm{Bu}$ açıdan üniversite rektörlerine önemli görevler düşmektedir. Üniversite yönetiminin proje odaklı bir yönetim anlayışına sahip olması (Whitchurch, 2007) ve değişen tüm koşullara üniversitelerin ayak uydurmasını sağlayarak bu değişime liderlik etmeleri beklenmektedir (Scott vd., 2010). Bu durumda projeleri ve planlarıyla kurumlarını her yönüyle geliştirecek ve değişimi yönetecek en uygun adayın rektör olarak seçilmesi bir gereklilik haline gelmektedir.

Ülkemizde 2547 sayılı yasa rektör seçilme süreci ile rektörün görev ve yetkilerini tanımlamaktadır. Yasada rektör seçilmek için "profesör akademik unvanına sahip olmak" koşulu tek kriter olarak ifade edilmiştir. Yönetsel bilgi, beceri ve tecrübenin bu görevi başarıyla yerine getirmek için bir gereklilik olduğunun aç1kça görülmesine rağmen bu göreve talip olmak için unvana ek bir koşulun aranmaması rektör seçim sürecinin kendisinin daha fazla öne çıkmasına neden olmaktadır (Erdoğmuş, 2014, s.45). 2016 yılı Ekim ayında yapılan yasal düzenlemeyle değişene kadar bu mevzuat gereği üniversitelerde gerçekleştirilen aday belirleme seçimleri sonrasında aldıkları oya göre sıralanan rektör adayları, bir sonraki aşamada Yükseköğretim Kurulu (YÖK) nezdinde aday sıralamalarının belirlenmesi aşamasında, gerçekleştirmek istedikleri projeleri ve üniversitelerinin performansını yükseltme yönünde ortaya koyacakları plan ve stratejileri 
sunmaktaydılar. Bu durumun yasada belirtilen zorunlu bir koşul olmaması; adayın bu aşamadaki performansının nihai karar üzerinde ne düzeyde etkisi olduğunu kesin olarak belirlemeyi imkansız kılmıştır. Yine de bu aşamanın önemli etkisi olduğunu düşünmek yanıltıcı olmayacaktır. Fakat mevcut durumda kaldırılmış olan, YÖK'e gönderilecek aday listesinin belirlendiği üniversitede gerçekleşen seçim sürecinde öğretim üyelerinin hangi beklentilerle oy kullandığı konusunda bir araştırma bulunmamaktadır.

$\mathrm{Bu}$ bakış açısıyla rektör adaylarının belirlendiği seçimlerde oy kullanan öğretim üyelerinin oy kararlarını verirken hangi kriterleri dikkate aldıklarını tespit etmek, bazı dönemlerde uygulanmasa da seçimle rektör belirleme yönteminin işleyişi hakkındaki değerlendirmelere farklı bir bakış açısı getirebilir. Ayrıca, yükseköğretim kurumlarında dekan, bölüm başkanı gibi farklı kademelerde yönetici atamalarında isteğe bağlı olarak uygulanmaya devam eden ve önerilecek yeni seçim yöntemlerine 1şık tutacaktır. Bu amaçla bu çalışmada, bir üniversitede rektör adayları belirleme seçimi sonrası öğretim üyelerinin oy kararlarını etkileyen kriterler tespit edilmiş ve bu kriterlerin seçmenin oyunu verdiği adayı belirlediği karar aşamasında ne düzeyde önem verdiği ölçülmeye çalışılmıştır.

\section{OY VERME DAVRANIŞI}

Demokratik yönetim modellerinin temel araçlarından birisi olan seçim mekanizması ülke yönetimlerinin belirlenmesi sürecindeki rolü açısından siyaset bilimi literatüründe seçmen davranışı kavramı altında incelenen bir konudur. Seçmen davranışları ülkeden ülkeye ve zaman içerisinde konjonktüre göre değişme gösterse de genel olarak ekonomik ve sosyolojik etmenler içerisinde değerlendirilir. Bu kapsamda oy verme davranışını açıklayan bütüncül bir model bulunmasa da, sosyolojik oy verme modeli (Berelson vd., 1954), sosyal psikoloji temelli psikososyal oy verme modeli (Campbell vd., 1960), ekonomik oy verme modeli (Downs, 1957) gibi temel modeller seçmen davranışlarını politik oy verme süreçleri için birçok yönüyle tanımlamaya çalışmaktadır. Bütün bu çabalar oy verme davranışını iyi analiz ederek seçime katılan kişi veya partilerin doğru stratejiler geliştirmesine ve seçim sonuçlarının doğru tahmin edilmesine katkı sağlamaktadır.

Bireyin seçim kararında işleyen temel karar verme mekanizmalarının psikolojik ve sosyolojik temelleri benzerlik gösterse de, yapılan çalışmalar her seçim durumunda konuya özgü etkenlerin seçim kararında oy verenler tarafından dikkate alındığını göstermektedir. Bu nedenle seçimlerin söz konusu olduğu her farklı konu için seçmen kararında dikkate alınan kriterlerin tespit edilmesi gerekmektedir. Literatürde politik seçim süreçleri dışında belirli bir seçmen kitlesinin oy kullanarak tercihlerini belirttikleri farklı durumlarda oy verme davranışını konu alan az sayıda çalışma bulunmaktadır. Bu çalışmaların büyük bölümü sendika seçimleriyle ilgilidir. Summers vd. (1986) sendika temsilci seçimlerinde oy verme davranışını etkileyen sebepleri kapsayan bir karar modeli önerisinde bulunmuşlardır. Martinez vd. (2011) sendika seçimlerinde bireyselliğin ve grup dayanışmasının oy davranışına etkilerini incelemişlerdir.

Seçmen davranışlarıyla ilgili bir diğer sınırlı çalışma alanı ise halka açık şirketlerin yönetsel süreçlerinin bir gereği olarak gerçekleşen gerçek ve tüzel 
kişiliklerin pay sahibi olarak oy verme davranışıdır. Iliev vd. (2015) halka açık şirketlerde pay sahiplerinin oy verme davranış çeşitlerini incelemişlerdir. Bew ve Fields (2012) yatırım fonlarında oy verme kararının nasıl gerçekleştiğini ortaya koymuşlardır. Choi vd. (2013) yatırım fonlarının pay sahibi olduğu şirketlerde oy verme kararlarını incelemişlerdir.

Üniversitelerde öğretim üyelerinin oy verme davranışıyla ilgili çalışmalar sendika seçimlerini kapsayan çalışmalarla sınırlıdır. Hammer ve Berman (1981) öğretim üyelerinin sendika temsilci seçimlerinde oy kararlarını etkileyen yönetsel karar verme konusundaki güven duygusunun, karar vermeye yönelik arzunun, uygulamalardan duyulan memnuniyetin ve ekonomik konulardaki memnuniyetin etkilerini regresyon analiziyle incelemişlerdir. Zalesny (1985) öğretim üyelerinin oy tercihlerinin tahmininde ekonomik ve ekonomik olmayan faktörlerin etkilerini değerlendirmiştir. Hemmasi ve Graf (1993) öğretim üyelerinin sendika temsilci seçiminde oy davranışını belirleyen etkenleri analiz etmişlerdir. Tüm bu çalışmalarda ortaya konan kriterler seçim konusu olan sendika yapısı ve oy verenler açısından yarattığı sonuçlar ile sınırlı kalmaktadır.

Literatürde yükseköğretim kurumlarında yönetici seçimiyle ilgili olarak sadece rektör seçimi konusunda az sayıda çalışma yer almaktadır. Bunda rektörün seçim yoluyla belirlenmesi uygulamasının fazla tercih edilmeyen bir yaklaşım olması ve çok az sayıda ülke tarafindan kullanılan bir yöntem olmasının rolü bulunmaktadır. Çelik ve Bekir (2014, s.23) yaptıkları incelemede Türkiye dışında seçim yöntemi kullanan ülkelerde rektörün; Kore'de akademik personelin; Slovenya'da öğrenci ve öğretim üyelerinin; Yunanistan'da personel, öğrenci ve öğretim üyelerinin oylarıyla seçildiğini tespit etmişlerdir. Türkiye'de rektör belirleme süreciyle ilgili çalışmalar rektör seçimi ve atamalarının karşılaştırılmalı olarak ele alındığı araştırmalardır. Doğramacı (2007) tarihsel süreç içerisinde dünyada rektör belirleme süreçlerini değerlendirmiştir. Mutlu (2009) devlet ve vakıf üniversitelerinde rektör belirleme süreçlerini incelemiş ve sorunları dile getiren eleştirel bir inceleme yapmıştır. Arap (2011) dünyadaki uygulamalarla birlikte Türkiye'de rektör belirleme süreçlerinde tarihsel gelişimi ve mevcut seçim sürecinin sorunlarını ele almıştır. Yapılan literatür taramasında yükseköğretim kurumlarında yönetici belirleme sürecinde oy verme davranışıla ilgili bir çalışmaya rastlanmamıştır.

\section{KRITTERLERIN BELIRLENMESİ}

Kriterlerin belirlenmesi sürecinde en az üç rektörlük sürecinde oy kullanmış ve ortalama 15 yıldır üniversitede görev yapan 6 öğretim üyesiyle yüz yüze görüşmeler yapılmıştır. Bu görüşmelerde ifade edilen deneyimlerden yola çıkarak öğretim üyelerinin oy kararına etki eden kriterler derlenmiştir. Beş başlık altında toplanan ifadeler daha sonra görüşme yapılan 6 öğretim üyesinin onayına sunularak belirlenmiştir. Bu kriterler aşağıdaki gibidir;

- Oy verenin, rektör seçiminde aday olan kişinin Cumhurbaşkanı tarafından atanabileceğine yönelik algısı (Cumhurbaşkanı Ataması). 
- Oy verenin, rektör seçiminde aday olan kişinin seçimde alabileceği toplam oy sayısına yönelik algısı (Oy Sayısı).

- Oy verenin, rektör seçiminde aday olan kişinin varsa geçmişte idari görevlerdeki performansı ve rektör seçilmesi halinde üniversite için ön gördügü proje ve planları hakkındaki algısı (Performans-Proje).

- Oy verenin, rektör seçiminde aday olan kişiyle olan kişisel, kurumsal veya fikri yakınlı̆̆ı (Adaya Yakınlık).

- Oy verenin vereceği oy karş1lığı rektör seçiminde adaydan kişisel beklentileri (Kişisel Beklentiler).

\section{KRITTER ÖNCELIKKLERININ BELİRLENMESI}

Oy verme kararı, seçmenin hangi adaya oy vereceğini belirlerken birden fazla kriterin dikkate alındığı planlı, sübjektif ve yargısal bir karar verme durumudur. $\mathrm{Bu}$ yapısıyla çok kriterli bir karar verme problemi olarak ifade edilebilir. Çok kriterli karar verme problemlerinin çözümünde tercihlerin sıralanmasına veya en iyi alternatifin seçilmesine yönelik çok sayıda karar vermeye yardımcı yöntem bulunmaktadır. Bu yöntemler karar probleminin yapısı, karar verici sayısı, amaç, yöntemin uygulama kolaylığı gibi birçok faktöre göre tercih edilmektedir. $\mathrm{Bu}$ yöntemlerin birçoğunda karar süreci hiyerarşik bir yapı olarak tanımlanmakta ve karar verme durumuna etki eden kriterlerin önem düzeyleri, her bir alternatifin bu kriterler açısından değerlendirilmesiyle analiz edilmektedir. Bu yöntemler içinde çok geniş kullanım alanı bulan ve karar vericinin sübjektif yargılarına dayalı karar verme durumlarında tercih edilen Saaty'nin (1980) geliştirdiği Analitik Hiyerarşi Süreci (AHP) yöntemi, bu çalışmada oy verme kararına etki eden kriterlerin önem derecelerinin belirlenmesi için tercih edilmiştir. Yöntemin tercihinde en önemli etken karar vericinin sübjektif yargılarını doğrudan puanlaması veya ağırlıklandırması yerine ikili karşılaştırmalar kullanarak değerlendirmesidir. Karşılaştırma yapmak beynin en temel çalışma prensibidir. Beyinde bilgiler daha önce bildiklerimizle kıyaslanarak anlamlandırılmakta ve hafızada yer almaktadır (Bahurmoz, 2006, s.4). AHP yönteminin önemli bir avantaj1 da çok kriterli karar verme yöntemleri arasında karar vericinin yargılarının tutarlılığını ölçen tek yöntem olmasıdır (Duran ve Aguilo, 2008, s.1788). Yöntemin etkinliği sağlık, eğitim, imalat, sosyal, endüstriyel, vb. birçok farklı konuda uygulama çalışmalarıyla test edilmiştir (Vaidya ve Kumar, 2006). Ayrıca yöntem seçim yapma, değerlendirme, planlama, sıralama, fayda-maliyet analizi ve tahmin konularını içeren karar verme durumlarında kullanılmıştır (Lee vd., 2001; Vaidya ve Kumar, 2006).

AHP yöntemi bireyin yargılarını sayısallaştırarak, yargının elde edilen sayısal ağırlıklarla nasıl ilişkilendirilmesi gerektiğini başarıyla ortaya koymaktadır (Saaty ve Ozdemir, 2003). Bunun için 1'den 9'a kadar kesikli bir ölçek kullanılmaktadır. Fakat uygulamada muğlaklık içeren durumlar için birey ikili karşılaştırma tercihlerini tam sayılarla ifade etmekte kararsız kalabilmektedir. Bu durumlarda AHP, bireyin yargıları sayılarla örtüştürmedeki belirsizliğini dikkate alamamaktadır. Bulanık AHP (BAHP) bu gibi durumlar için geliştirilmiş bir 
yöntemdir. BAHP, AHP yöntemine kıyasla karmaşık hesaplamalar içermektedir ve bu konuda farklı yaklaşımlar geliştirilmiştir. Bulanık AHP yöntemiyle ilgili ilk çalışma Laarhoven ve Pedrycz (1983) tarafından gerçekleştirilmiştir. Daha sonraları BAHP için farklı yaklaşımlar önerilmiştir (örn: Buckley, 1985; Chang, 1996; Csutora ve Buckley, 2001). Bu yöntemler içinde Chang'in (1996) yöntemi uygulama kolaylığ 1 sebebiyle birçok çalışmada tercih edilen bir yaklaşım olmuştur. Fakat bu yaklaşım, Wang, Luo ve Hua'nın (2008) belirtmiş olduğu gibi bazı unsurlara (kriter, alt kriter, alternatif) sıfır ağırlık hesaplayıp, yanlış kararlara yol açmaktadır. Bu çalışmada Buckley'in (1985) ve Csutora ve Buckley'in (2001) orijinal AHP yönteminin bulanıklaştırılmış biçimi olarak ortaya koydukları LamdaMaks yöntemleri kriter ağırlıklarının hesaplanması için kullanılmış ve sonuçların tutarlılığı iki yöntem sonuçları karşılaştırılarak test edilmiştir.

BAHP yöntemi bulanık küme teorisi üzerine kurgulanmıştır ve karar vericinin kriterlere yönelik değerlendirmeleri sözel değişkenler kullanılarak hesaplanmaktadır. Sözel değişkenler, değişkenin değerinin sözel ifadeler kullanılarak belirtildiği değişkenler olarak tanımlanmaktadır (Önüt vd., 2008, s.445). Bu değişkenler bulanık sayılarla ifade edilmektedir. Çalışmalarda en çok tercih edilen bulanık sayılar, üçgensel ve yamuk bulanık sayılardır. Bu çalışmada üçgensel sayılar ikili karşılaştırma ölçeği için tercih edilmiştir.

Bulanık sayılar, bulanık kümelerin $B=\left\{\left(x, \mu_{B}(x), x \in R\right\}\right.$ özel bir halidir. $x$ gerçel bir sayı değeri alır ve $\mu_{B}(x)$ bu değerin sürekli $[0,1]$ kapalı aralığında yansımasını oluşturur. Bir üçgensel bulanık sayı $A=(k, o, b)$ şeklinde ifade edilebilir. Bu ifadede $k$ parametresi bulanık bir yargının alabileceği en küçük değeri, $o$ olması muhtemel en olası değeri, $b$ ise alabileceği en büyük değeri göstermektedir. $A$ bulanık sayısına ait üçgensel üyelik fonksiyonu aşağıda belirtilmiştir.

$$
\mu_{A}(x)=\left\{\begin{array}{cl}
0 & x<k \\
(x-k) /(o-k) & k \leq x \leq o \\
(b-x) /(b-o) & o \leq x \leq b \\
0 & x>b
\end{array}\right.
$$

Bu çalışmada kullanılan sözel değişkenler ve onlara karşılık gelen üçgensel bulanık sayıları içeren ölçek Tablo 1'de gösterilmektedir.

Tablo 1. Kriter Önem Düzeylerini Belirlemekte Kullanılan Sözel Değişkenler

\begin{tabular}{lc}
\hline Önem düzeyi sözel ölçeği & Üçgensel bulanık ölçek \\
\hline Eşit Derecede Önemli & $(1,0 ; 1,0 ; 1,0)$ \\
Orta Derecede Önemli & $(1,0 ; 3,0 ; 5,0)$ \\
Kuvvetli Derecede Önemli & $(3,0 ; 5,0 ; 7,0)$ \\
Çok Kuvvetli Derecede Önemli & $(5,0 ; 7,0 ; 9,0)$ \\
Aşırı Derecede Önemli & $(7,0 ; 9,0 ; 9,0)$ \\
\hline
\end{tabular}

Çalışmanın bu bölümünde Buckley'in (1985) ve Csutora ve Buckley'in (2001) BAHP yönteminin ağırlık hesaplama aşamaları kısaca açıklanmıştır. 


\section{A. Buckley'in BAHP Yöntemi}

$\mathrm{Bu}$ yöntemde yamuk bulanık sayılar kullanılarak geometrik ortalama metodu yöntemiyle bulanık ağırlıklar hesaplanmıştır. Bu hesaplamalarda bulanık çarpma işlemi ve bulanık $n$ 'inci kuvvetten kök alma işlemleri gerçekleştirilmektedir. Karşılaştırma matrisinde tüm $i$ ve $j$ değerlerinin $x_{i j}=\left(k_{i j}\right.$, $o_{i j}$, $\left.b_{i j}\right)$ üçgensel bulanık sayı olduğu durumda geometrik ortalama değeri formül 2'de verildiği şekilde her bir karar verici için hesaplanmaktadır:

$$
\tilde{Z}_{i}=\left[\prod_{j=1}^{n} x_{i j}\right]^{1 / n}
$$

Buna göre bulanık ağırlı $\widetilde{W}_{i}$ formül 3'deki gibi hesaplanmaktadır:

$$
\widetilde{W}_{i}=\tilde{Z}_{i} \otimes\left[\sum_{j=1}^{n} \tilde{Z}_{j}\right]^{1 / n}
$$

$\otimes$ simgesi bulanık çarpım işlemini temsil etmektedir.

\section{B. Csutora ve Buckley'in BAHP Yöntemi}

Lambda-max metodu olarak adlandırılan bu yöntemde her bir karar verici için bulanık ağırlıklar aşağıdaki adımlarla hesaplanmaktadır.

$\alpha=1$ ise, $w_{o}$ ağırlık matrisi AHP yöntemi uygulanarak hesaplanır:

$$
w_{o}=\left[w_{i o}\right], \quad i=1,2, \ldots, n
$$

$\alpha=0$ ise, $w_{k}$ ve $w_{b}$ ağırlıklar matrisi AHP yöntemi uygulanarak hesaplanır:

$$
\begin{array}{ll}
w_{k}=\left[w_{i k}\right], & i=1,2, \ldots, n \\
w_{b}=\left[w_{i b}\right], & i=1,2, \ldots, n
\end{array}
$$

Hesaplanacak ağılıkların bulanıklığının korunması için iki sabit değer $\left(S_{k}\right.$ ve $S_{b}$ ) aşağıdaki şekilde hesaplanır:

$$
\begin{aligned}
& S_{k}=\min \left\{\frac{w_{i o}}{w_{i k}}, 1 \leq i \leq n\right\} \\
& S_{b}=\operatorname{maks}\left\{\frac{w_{i o}}{w_{i b}}, 1 \leq i \leq n\right\}
\end{aligned}
$$

Ağırlık matrisinin alt $\operatorname{sınırı~}\left(w_{k}\right)$ ve üst $\operatorname{sinırı~}\left(w_{b}\right)$ aşağıdaki şekilde hesaplanmaktadir:

$$
\begin{array}{lll}
w_{k}{ }^{*}=\left[w_{i k}{ }^{*}\right], & w_{i k}{ }^{*}=S_{k} w_{i k} & i=1,2, \ldots, n \\
w_{b}{ }^{*}=\left[w_{i b}{ }^{*}\right], & w_{i b}{ }^{*}=S_{b} w_{i b} & i=1,2, \ldots, n
\end{array}
$$

$w_{k}{ }^{*}, w_{b}{ }^{*}$ ve $w_{o}$ ağırlıkları birleştirilerek her bir karar verici için bulanık ağırlık değerleri aşağıdaki şekilde oluşturulur:

$$
\widetilde{W}_{i}=\left(w_{k}^{*}, w_{o}, w_{b}^{*}\right), \quad i=1,2, \ldots, n
$$

AHP ve BAHP uygulamalarında birden çok karar vericinin değerlendirmelerinin birleştirilmesinde tercih edilen yaklaşım geometrik ortalama yaklaşımıdır. $\mathrm{Bu}$ yaklaşımda $\mathrm{g}$ karar vericinin bulanık kriter ağıllıkları aşağıda belirtildiği gibi hesaplanmaktadır;

$$
k_{i}=\left(\prod_{g=1}^{G} k_{i g}\right)^{1 / G}, o_{i}=\left(\prod_{g=1}^{G} o_{i g}\right)^{1 / G}, b_{i}=\left(\prod_{g=1}^{G} b_{i g}\right)^{1 / G}, g=1,2, \ldots, G
$$


$\mathrm{Bu}$ çalışmada her iki yöntemde elde edilen bulanık ağırlıkların durulaştırılması için aşağıdaki formül kullanılmış ve iki yöntem sonuçları karşılaştırıldığında durulaştırma sürecinde ortaya çıkabilecek farklılaşmaların etkisi yok edilmiştir.

$$
W_{i}=\left(k_{i}+2 o_{i}+b_{i}\right) / 4
$$

\section{Anket Tasarımı}

Görüş toplamaya yönelik anketlerde amaca göre çok çeşitli soru tipi kullanılmaktadır. Araştırmacılar açısından anket yönteminin kullanımında en temel sorun cevap verenin algısının doğru ve kesin biçimde ölçülebilmesidir (Traugott ve Lavrakas, 2000). Öyle ki görüş anketlerinde aynı içeriğin farklı tipte sorularla sorgulanması farklı cevaplar verilmesine neden olabilmektedir (Sato, 2005). Belirli sayıda alternatifin önem düzeyi veya ağırlığının belirlenmesinde tercih edilen en basit ve anlaşılması kolay yöntem alternatiflerin doğrudan puanlandığı soru tipidir. Fakat bu yöntemin ne düzeyde insan algısını ölçebildiği şüpheli bir konudur. Sato (2009) çalışmasında üç farklı soru tipinin insan algısını ölçmedeki etkinliğini değerlendirmiştir. Çalışmada, alternatiflerin ağırlıklarının belirlenmesi için hazırlanan 0-100 arasında puanlama yapılmasını gerektiren Duyulanım Termometresi soruları, çoktan seçmeli sorularla ve AHP ikili karşılaştırma tipi sorularla politik tutumun değerlendirilmesine yönelik bir anket kullanılarak karşılaştırılmıştır. Analiz sonuçları AHP ikili karşılaştırma soru tipinin diğer iki tip soruya göre üstün olduğunu ve insan algısını ölçmede daha tutarlı sonuçlar verdiğini tespit etmiş̧ir. Ayrıca AHP ikili karşılaştırma tipi sorularla elde edilen alternatif ağırlıklarının da cevap verenlerin tercihlerini daha doğru yansıttığını ortaya koymuştur.

Anket soru tipleriyle ilgili bir başka sorun da anket içeriğinin kişilerin paylaşmaya çekindiği konular hakkında olduğu zamanlarda ortaya çıkabilmektedir. Soru tipine göre verilen cevapların sonuçlarının çoktan seçmeli sorularda veya puanlama gerektiren soru tiplerinde olduğu gibi açıkça anlaşılır olması, cevap verenin verdiği cevabın kendini kolayca ele vereceği çekincesiyle gerçek düşüncesi yerine ideal durumu gösteren veya olması gerektiğini düşündüğ̈̈ cevapları vermesine yol açabilmektedir. Bu gibi durumlarda AHP ikili karşılaştırma soru tipi cevap verenin çekincelerini giderebilir. Çünkü bu soru tipinde sonuçların verilen cevaplara bakarak kolayca anlaşılması mümkün olmamakta, değerlendirme ancak matematiksel hesaplama sonucu ortaya konabilmektedir.

\section{ARAŞTIRMA BULGULARI}

Çalışmada belirlenen kriterlerin geçerliliği açısından, 2014 Ekim ayında rektör aday belirleme seçimi gerçekleştirilen 9 üniversitenin tümüne çevre koşullarının tüm seçmenler için aynı olacağı varsayılan oy verme tarihiyle Cumhurbaşkanı tarafından rektör atamalarının yapılacağı zaman aralığında ulaşılmak istenmiştir. Fakat çalışmanın zaman ve bütçe kısıtları nedeniyle çalışma sadece bir üniversitede seçmen olarak tanımlanan öğretim üyeleri kullanılarak gerçekleştirilmiştir. 
Toplam 589 öğretim üyesinin seçmen olarak yer aldığ1 seçimlerde seçmenlerin \%15'i (91) Profesör, \%26's1 (152) Doçent ve \%59'u (346) Yardımc1 Doçent kadrosundadır. Rektör belirleme seçiminde oy verme davranışında dikkate alındığı varsayılan 5 kriterin ikili karşılaştırmalarını içeren anket, oy verme işleminin tamamlanmasını izleyen bir ay içerisinde yüz yüze görüşmelerle çalışmanın konusu ve amacı anlatılıp anketin nasıl doldurulması gerektiği açıklanarak gerçekleştirilmiştir. Çalışmada veri toplama için öngörülen zaman aralığı seçmenin gerçekleşmiş oy kararında dikkate aldığı düşünceleri doğru şekilde yakalamak için seçimin yapılmasını takiben başlatılmış ve YÖK'te ilk üç adayın açıklandığı zamana kadar sürdürülmesi planlanmıştır. Böylece seçim sonucunun kısmen de olsa bilinmesinin seçmenin kriterlere atfettiği önem düzeyinde yaratabileceği etki engellenmiştir. Veri toplamada belirlenen bu süre içerisinde ana kütlenin tamamına ulaşmak mümkün olmamıştır. $\mathrm{Bu}$ nedenle, oransal olarak seçmenlerin unvanlara göre dağılımları nispetinde temsili bir örnekleme ulaşmak amacıyla 126 öğretim üyesine anketler uygulanmıştır. Bu çalışma kapsamında kriter ağırlık değerlerinin tespiti ancak ikili karşılaştırma anketine verilen cevapların tutarlı olması koşuluyla güvenilir olacaktır.

$\mathrm{Bu}$ çalışmada ikili karşılaştırmaların tutarlılıkları üçgensel sayıların $o_{i}$ değerleri kullanılıp Saaty'nin (1995, s.81) tutarlılık oran1 (CR) hesaplanarak test edilmiştir. CR bir değerlendirme matrisinin tutarlılık indeksinin (CI) rassal bir matrisin tutarlılığına (RC) oranlanarak hesaplanmaktadır. CR'nin hesaplanmasında $\lambda_{\text {maks }}$ kullanılır. Buna göre:

$$
C I=\left(\lambda_{\text {maks }}-n\right) /(n-1) \quad \text { ve } \quad C R=C I / C R \leq 0,1
$$

Çalışmada kriterlerin bulanık ağırlıkları hesaplanmadan önce anketlerdeki ikili karşılaştırmaların tutarlılıkları test edilmiş ve tutarlı olmayan 32 anket sonucu analize dahil edilmemiştir. Tutarlılığı (CR) 0,1 değerinin altında olan 94 katılımcının 14'ü (\%15) Profesör, 25'i (\%27) Doçent ve 55'i (\%59) Yardımcı Doçent kadrosunda çalışan öğretim üyeleridir. Bu örneklemin unvanlara göre dağılımı, ana kütledeki dağılımı tam olarak yansıttığı için bu çalışmada unvanlar düzeyinde temsili bir örnekleme ulaşılmıştır.

Tablo 2. Birleştirilmiş İkili Karşılaştırma Değerleri $(\mathrm{CR} \leq 0,1, \mathrm{n}=94)$

\begin{tabular}{|c|c|c|c|c|c|}
\hline & $\mathrm{CA}$ & OS & PP & AY & KB \\
\hline $\begin{array}{c}\text { Cumhurbaşkanı } \\
\text { Ataması (CA) }\end{array}$ & $(1 ; 1 ; 1)$ & $(0,973 ; 1,355 ; 1,904)$ & $(0,312 ; 0,389 ; 0,549)$ & $(0,528 ; 0,760 ; 1,180)$ & $(0,888 ; 1,428 ; 2,216)$ \\
\hline Oy Sayısı (OS) & $(0,525 ; 0,738 ; 1,027)$ & $(1 ; 1 ; 1)$ & $(0,243 ; 0,309 ; 0,446)$ & $(0,435 ; 0,624 ; 0,939)$ & $(0,739 ; 1,130 ; 1,652)$ \\
\hline $\begin{array}{l}\text { Performans- } \\
\text { Proje (PP) }\end{array}$ & $(1,823 ; 2,570 ; 3,206)$ & $(2,242 ; 3,234 ; 4,113)$ & $(1 ; 1 ; 1)$ & $(1,641 ; 2,506 ; 3,413)$ & $(2,178 ; 3,075 ; 3,783)$ \\
\hline $\begin{array}{l}\text { Adaya Yakınlık } \\
\text { (AY) }\end{array}$ & $(0,847 ; 1,315 ; 1,894)$ & $(1,065 ; 1,602 ; 2,298)$ & $(0,293 ; 0,399 ; 0,609)$ & $(1 ; 1 ; 1)$ & $(1,075 ; 1,614 ; 2,106)$ \\
\hline $\begin{array}{c}\text { Kişisel } \\
\text { Beklentiler } \\
\text { (KB) }\end{array}$ & $(0,451 ; 0,700 ; 1,126)$ & $(0,605 ; 0,885 ; 1,354)$ & $(0,264 ; 0,325 ; 0,459)$ & $(0,475 ; 0,619 ; 0,930)$ & $(1 ; 1 ; 1)$ \\
\hline
\end{tabular}

Çalışmada verilerin analizi ilk aşamada her bir anketten elde edilen bulanık ikili karşılaştırmalar formül (2)-(3) uygulanarak Buckley'in BAHP yöntemiyle ve formül (4)-(11) kullanılarak Csutora ve Buckley'in BAHP yöntemiyle kriterlerin bulanık ağılık değerleri Excel programı yardımıyla hesaplanmıştır. Sonraki 
aşamada tüm katılımcıların bulanık kriter ağırlık değerleri geometrik ortalama yöntemiyle birleştirilmiştir (Tablo 2). Bireysel değerlendirmelerin birleştirilerek tek bir değerlemede ifade edilebilmesine yönelik temel ilke, birleştirilecek kararların homojen olarak dağılmasıdır. Heterojen dağılım gösteren durumlarda belirli bir ölçüt kullanarak oluşturulacak gruplar için değerlendirmelerin birleştirilmesi sağlıklı sonuç verecektir. Bu nedenle bu çalışmada ilk olarak tüm katılımcıların değerlendirme sonuçları birleştirilerek analiz edilmiş, daha sonra rektör belirleme seçiminde oy kullanan öğretim üyelerinin gerek mesleki tecrübenin, gerekse hizmet yılının ve kurumsal ilişkilerin bir göstergesi olan unvanları nedeniyle birbirlerinden farklı yargılara sahip olabilecekleri düşünülmüş ve unvanlara göre değerlendirmeler birleştirilerek sonuçlar karşılaştırılmıştır.

Şekil 1. Buckley BAHP ve Csutora ve Buckley BAHP Yöntemleriyle Hesaplanan Bulanık Ağırlıklar

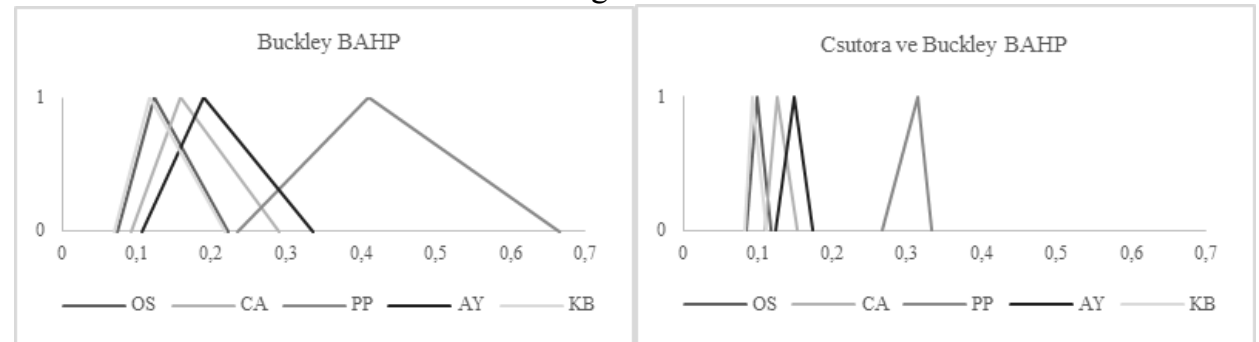

OS: Oy Sayısı; CA: Cumhurbaşkanı Ataması; PP: Performans-Proje; AY: Adaya Yakınlık; KB: Kişisel Beklentiler

Şekil 1 Buckley BAHP ve Csutora ve Buckley BAHP yöntemleri kullanılarak hesaplanmış ve geometrik ortalama metoduyla birleştirilmiş bulanık kriter ağırlık değerlerini göstermektedir. İki yöntemde hesaplanan kriter ağırlıkları aynı öncelikle sıralanmaktadır. Bu sonuçlara göre kriterler şöyle sıralanmıştır: Performans-Proje, Adaya Yakınlık, Cumhurbaşkanı Ataması, Oy Sayısı, Kişisel Beklentiler. İki yöntem bulanık kriter ağırlıkları karşılaştırıldığında Buckley BAHP yöntemiyle hesaplanan üçgensel bulanık sayı değerlerinde $k_{i}$ ve $b_{i}$ değerleri arasındaki farkın çok daha büyük olduğu görülmektedir. Yapılan çalışmalarda bu aralığın fazla olduğu durumlar genellikle kullanılan yönteme göre ihtiyaç duyulan bulanık işlem sayısından kaynaklandığı öne sürülmektedir (Mikhailov, 2003, s.367). Ağıllıkların durulaştırılması açısından $k_{i}$ ve $b_{i}$ değerleri arasındaki farkın az olması durulaştırma için kullanılacak farklı yaklaşımların hesaplayacağı değerler arasında farklılaşmayı azaltacak ve sonuçların daha tutarlı olmasını sağlayacaktır. Bu bakış açısıyla Csutora ve Buckley'in BAHP yönteminde ulaşılan bulanık kriter ağırlıkları daha az yayılan değerler içerdiği için durulaştırma sonuçları daha sağlıklı olarak kriter yargılarının ayrışmasını sağlayacaktır. Tablo 3 Buckley'in BAHP ve Csutora ve Buckley'in BAHP yöntemleriyle hesaplanan bulanık kriter ağırlıkları ve bu ağırlıkların formül (13) kullanılarak durulaştırılmış ağırlık değerlerini göstermektedir. Durulaştırılmış ağırlık değerleri karşılaştırıldığında iki yöntemin sonuçlarının aynı olduğu görülmektedir. 
Tablo 3. Birleştirilmiş Kriter Değerlendirmeleri

\begin{tabular}{lcccc}
\hline \multirow{2}{*}{ Kriter } & \multicolumn{2}{c}{ Buckley BAHP } & \multicolumn{2}{c}{ Csutora ve Buckley BAHP } \\
& $\widetilde{W}_{i}$ & $W_{i}$ & $\widetilde{W}_{i}$ & $W_{i}$ \\
\hline Cumhurbaşkanı Ataması (CA) & $(0,093 ; 0,159 ; 0,291)$ & 0,163 & $(0,109 ; 0,126 ; 0,152)$ & 0,165 \\
Oy Sayısı (OS) & $(0,073 ; 0,124 ; 0,222)$ & 0,126 & $(0,085 ; 0,099 ; 0,117)$ & 0,128 \\
Performans-Proje (PP) & $(0,235 ; 0,410 ; 0,665)$ & 0,399 & $(0,265 ; 0,315 ; 0,333)$ & 0,394 \\
Adaya Yakınlık (AY) & $(0,107 ; 0,190 ; 0,336)$ & 0,191 & $(0,124 ; 0,148 ; 0,174)$ & 0,191 \\
Kişisel Beklentiler (KB) & $(0,070 ; 0,118 ; 0,218)$ & 0,122 & $(0,082 ; 0,092 ; 0,112)$ & 0,122 \\
\hline
\end{tabular}

Analizin ikinci aşamasında katılımcıların bulanık ikili karşılaştırma değerlendirmeleri unvanlara göre geometrik ortalama yöntemi kullanılarak birleştirilmiş ve Csutora ve Buckley'in BAHP yöntemiyle kriterlerin bulanık ağırlıkları hesaplanmıştır. Şekil 2'de Yardımcı Doçent, Doçent, Profesör ve tüm katılımcıların bulanık kriter ağırlıkları gösterilmektedir. Genel olarak kriter öncelik sırası unvanlara göre farklılık göstermese de bulanık kriter ağırlıkları farklılaşmaktadır. Üç unvan grubu için Performans-Proje kriteri ilk sırada yer almaktadır, ancak doçentler için bulanık ağırlığı daha fazladır. Yardımcı doçentler için Cumhurbaşkanı Ataması kriteri Adaya Yakınlık kriterinin biraz üzerinde ağırlıklandırılmıştır. Profesörler için ilk üç kriterin bulanık ağırlıklarının birbirine çok yaklaştı̆̆1 görülmektedir.

Şekil 2. Unvanlara Göre ve Birleştirilmiş Veri İçin Bulanık Ağırlıklar

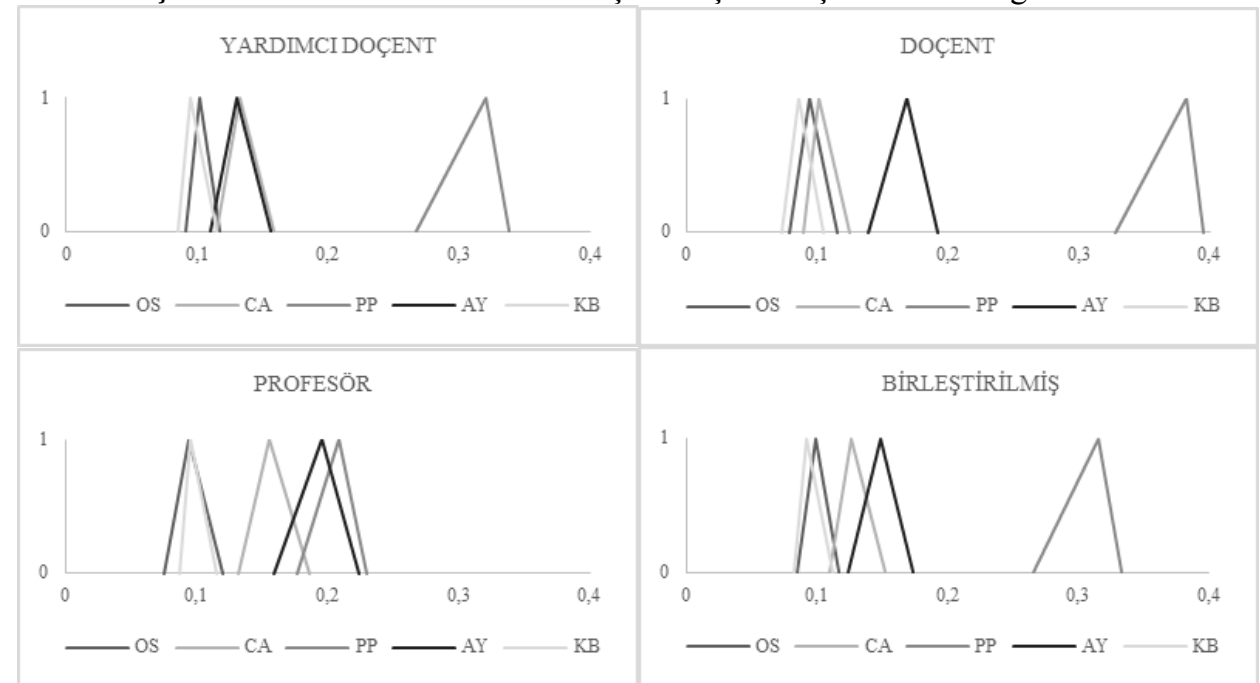

OS: Oy Sayısı; CA: Cumhurbaşkanı Ataması; PP: Performans-Proje; AY: Adaya Yakınlık; KB: Kişisel Beklentiler

Bulanık kriter ağırlıkları formül (13) kullanılarak durulaştırılmıştır. Unvanlara göre kriter ağırlıkları incelendiğinde; Doçentlerin Performans-Proje kriterine \%45 ağırlıkla en fazla önemi atfettiği, ikinci sırada ise \%40 ile yardımc1 doçentlerin bu kriteri dikkate aldığı görülmektedir. Profesörler \%20 ve üzeri oranda birbirine çok yakın değerlenen üç kriteri oy kararını verirken dikkate almaktadırlar. 
Tablo 4. Durulaştırılmış Kriter Ağırlıkları

\begin{tabular}{lcccc}
\hline Kriter & Yardımcı Doçent & Doçent & Profesör & Birleştirilmiş \\
\hline Cumhurbaşkanı Ataması (CA) & 0,173 & 0,126 & 0,209 & 0,165 \\
Oy Sayısı (OS) & 0,132 & 0,116 & 0,128 & 0,128 \\
Performans-Proje (PP) & 0,400 & 0,450 & 0,274 & 0,394 \\
Adaya Yakınlık (AY) & 0,170 & 0,202 & 0,258 & 0,191 \\
Kişisel Beklentiler (KB) & 0,125 & 0,106 & 0,130 & 0,122 \\
\hline
\end{tabular}

\section{SONUÇ VE ÖNERILER}

Üniversitelerde rektörlerin atanmaları öncesi belirleyici ilk aşama olan rektör adaylarının belirlendiği seçim süreci periyodik olarak üniversiteler özelinde ve kamuoyunda farklı tartışmalara konu olmuştur. Özellikle kurumsallaşması henüz tamamlanmamış devlet üniversitelerinde yaşanan seçim süreçleri çoğu zaman öğretim üyelerinin gündemini gereğinden fazla meşgul etmekte ve gereksiz ayrışmalara ve iç çekişmelere neden olmuştur. Bu ve benzeri konular sebebiyle ve dünyada bu uygulamanın artık terk edilmeye başlaması ile rektör seçim sürecinde değişiklik talep ve önerileri gündeme zaman zaman gelmiş ve sonuçta 2016 yılı Ekim ayında yapılan yasal düzenlemeyle seçim uygulaması yürürlükten kaldırılmıştır. Bu sistemin işleyişini seçmen öğretim üyelerinin oy kararlarını etkileyen kriterler açısından incelemek, yükseköğretim kurumlarında seçim yoluyla dekan ve bölüm başkanı gibi farklı kademelerdeki yönetici atamalarına yönelik uygulamalara ve etkilerinin görünürlügünün fazla olması sebebiyle rektör seçimleri odağında gerçekleşen tartışmalara farklı bir bakış açısı getirebilir.

Elde edilen sonuçlar incelendiğinde, çalışmanın yapıldığı üniversite rektör seçimlerinde çalışmaya katılan öğretim üyelerinin oy verme kararında en fazla oranda adayın geçmişte idari görevlerdeki performansı ve rektör seçilmesi halinde üniversite için ön gördüğü proje ve planlarının etkili olduğu görülmektedir. Oy verme kararında ikinci olarak adayın Cumhurbaşkanı tarafından atanabileceğine yönelik algının etkili olduğu görülmektedir. Oy verenin adaya olan kişisel, kurumsal veya fikri yakınlığı oy verme kararını üçüncü düzeyde etkilemektedir. Son iki sırada oy verenin adayın seçimde alabileceği oy sayısına yönelik algısı ve oy karşı1lığ adaydan kişisel beklentiler yer almıştır. Ana kütlenin unvanlar düzeyinde temsili bir örneklemiyle gerçekleştirilen bu çalışmada elde edilen sonuçların tüm seçmenlerin oy kararında etkili olduğunu ileri sürmek için istatistiksel bir dayanak bulunmamakla birlikte elde edilen sonuçlar çalışma öncesinde ön görülen sonuçlarla büyük ölçüde örtüşmektedir.

Unvanlara göre hesaplanan kriter ağıllıkları incelendiğinde Yardımcı Doçentler ve Doçentler açısından tek bir kriterin oy kararına etkisi çok yüksek iken Profesörler için üç kriterin birbirine çok yakın oranlarla öne çıktığı ve oy kararı verilirken dikkate alındığı gözlenmiştir. Unvanların zamana bağlı olarak değiştiği düşünüldüğünde kişinin mesleki tecrübesinin, iş ilişkilerinin, statüsünün Yardımc1 Doçentlikten Profesörlüğe uzanan süreçte arttığı varsayılabilir. Bu durumda Profesörlerin oy verme kararında dikkate aldıkları kriterlerin ağırlıklara göre sıralamadaki yerleri diğer unvanlara kıyasla aynı kalsa da, Yardımcı Doçent ve 
Doçentlerde olduğu gibi tek bir kriterin baskın şekilde öne çıkamamış olması anlaş1ır bir durumdur.

Bu çalışmanın uygulama süreci başında farklı üniversiteler de çalışmaya dahil edilmiş ve aynı dönemde rektör belirleme seçimi gerçekleştiren dört üniversitede ikili karşılaştırma anketleri her bir üniversiteden birer araştırmacı aracılığıyla eş zamanlı olarak uygulamaya konmuştur. Fakat konunun öğretim üyeleri yönünden hassas bir konu olması, çalışmaya şüpheyle yaklaşmalarına ve anketi doldurmaktan kaçınmalarına sebep olmuştur. Üniversitelerde katılımın az sayıda olması sebebiyle bu üniversitelerde çalışmanın tekrarı mümkün olmamıştır. Farklı üniversitelerde veri toplamada yaşanan bu deneyimler ve katılımcıların yorumları seçim sürecinin öğretim üyeleri açısından nasıl tedirginlikler yaratığının bir göstergesi olarak algılanabilir. Bu nedenle, yükseköğretim kurumlarında seçmen davranışlarını iyi anlamak, seçim yönteminin yükseköğretim kurumlarında uygulanmasına yönelik karar vericilerin gerçekleştirecekleri düzenlemelerde dikkate alınması gereken önemli bir konudur.

Her bilimsel çalışmada olduğu gibi çalışma kapsamı ve kısıtları dikkate alındığında, bir üniversitede yaşanan rektör seçim sürecinde gerçekleştirilen bu çalışma sonuçlarını yükseköğretim kurumlarında tüm yönetici seçim süreçleri için genellemek mümkün değildir. Başka üniversitelerde de bu tür çalışmaların farklı çevre koşulları altında tekrar edilmesi öğretim üyelerinin seçmen davranışlarındaki değişkenliğin nedenlerinin daha iyi anlaşılmasına katkı sağlayacaktır.

\section{KAYNAKÇA}

Arap, S. K. (2011). “Türkiye'de Rektör Belirleme Süreci ve "Mütevelli Heyeti” Tartışmaları". Memleket Siyaset Yönetim, 6(16), 1-32.

Bahurmoz, A. M. (2006). "The analytic hierarchy process: a methodology for win-win management". JKAU: Econ. \& Adm, 20(1), 3-16.

Berelson, B. R., Lazarsfeld, P. F. ve Mcphee, W. N. (1954). Voting: a study of opinion formation in a presidential campaign. Chicago: Chicago University Press.

Bew, R. ve Fields, R. (2012). Voting decisions at US mutual funds: How investors really use proxy advisers, IRRC Institute.

Buckley, J. J. (1985). "Fuzzy hierarchical analysis". Fuzzy Sets and Systems, 17(3), 233-247.

Campbell, A., Converse, P. E., Miller, W. E. ve Stokes, D. E. (1960). The american voter. New York: Willey.

Chang, D.-Y. (1996). “Applications of the extent analysis method on fuzzy AHP”. European Journal of Operational Research, 95(3), 649-655.

Choi, S., Fisch, J. ve Kahan, M. (2013). "Who Calls the Shots: How Mutual Funds Vote on Director Elections". Harvard Business Law Review, 3, 35-81.

Csutora, R. ve Buckley, J. J. (2001). "Fuzzy hierarchical analysis: The Lamda-Max method". Fuzzy Sets and Systems, 120, 181-195.

Çelik, Z. ve Bekir, S. (2014). "Yükseköğretim sistemlerinin yönetimi ve üniversite özerkliği: Küresel eğilimler ve Türkiye örneği”. Yükseköğretim ve Bilim Dergisi, 4(1), 18-27.

Doğramac1, İ. (2007). Türkiye'de ve dünyada yükseköğretim yönetimi. Ankara: Meteksan A.Ş.

Downs, A. (1957). An economic theory of democracy. New York: Harper.

Durán, O. ve Aguilo, J. (2008). "Computer-aided machine-tool selection based on a Fuzzy-AHP approach". Expert Systems with Applications, 34(3), 1787-1794.

Erdoğmuş, N. (2014). "Türkiye'de Üniversite Rektörlerinin Sosyo-Demografik Özellikleri ve Kariyer Hazırlıkları”. Yükseköğretim Dergisi, 4(1), 44-53.

Hammer, T. H. ve Berman, M. (1981). "The role of noneconomic factors in faculty union voting". Journal of Applied Psychology, 66(4), 415-421. 
Hemmasi, M. ve Graf, L. A. (1993). "Determinants of faculty voting behavior in union representation elections: A multivariate model". Journal of Management, 19(1), 13-32.

Iliev, P., Lins, K. V., Miller, D. P. ve Roth, L. (2015). "Shareholder Voting and Corporate Governance Around the World". Review of Financial Studies, 28(8), 2167-2202.

Lee, W.B., Lau, H., Liu, Z. ve Tam, S. (2001). "A fuzzy analytic hierarchy process approach in modular product design". Expert Systems, 18(1), 32-42.

Martinez, A. D., Fiorito, J. ve Ferris, G. R. (2011). "Solidarity Revisited: Group-level Effects on Individual-level Union Voting". Journal of Labor Research, 32(1), 61-74.

Mikhailov, L. (2003). "Deriving priorities from fuzzy pairwise comparison judgements". Fuzzy Sets and Systems, 134, 365-385.

Mutlu, L. (2009). Devlet ve vakıf üniversiteleri: Rektör seçiminin önemi. İstanbul: Yalın Yayıncılık.

Önüt, S., Soner Kara, S. ve Efendigil, T. (2008). "A hybrid fuzzy MCDM approach to machine tool selection". Journal of Intelligent Manufacturing, 19(4), 443-453.

Royes, G. F. ve Bastos, R. C. (2001). "Political analysis using fuzzy MCDM". Journal of Intelligent \& Fuzzy Systems, 11(1,2), 53-64.

Saaty, T. L. (1980). The analytic hierarchy process. New York: McGraw-Hill.

Saaty, T. L. (1995). Decision making for leaders: the analytical hierarchy process for decisions in a complex world. Pittsburgh: RWS Publications.

Saaty, T. L. ve Ozdemir, M. S. (2003). "Why the magic number seven plus or minus two". Mathematical and Computer Modelling, 38(3-4), 233-244.

Sato, Y. (2005). "Questionnaire design for survey research: Employing weighting method". Içinde Proceedings of the Eighth International Symposium on the Analytic Hierarchy Process.

Sato, Y. (2009). "How to Measure Human Perception in Survey Questionnaires". International Journal of the Analytic Hierarchy Process, 1(2).

Scott, G., Bell, S., Coates, H. ve Grebennikov, L. (2010). "Australian higher education leaders in times of change: The role of ProVice-Chancellor and Deputy Vice-Chancellor". Journal of Higher Education Policy and Management, 32(4), 401-418.

Summers, T. P., Betton, J. H. ve Decotiis, T. A. (1986). "Voting For and Against Unions: A Decision Model". Academy of Management Review, 11(3), 643-655.

Traugott, W. M. ve Lavrakas, J. P. (2000). The Voter's Guide to Election Polls, 2ed. New York: Chatham House Publishers, Seven Bridges Press, LLC.

Vaidya, O. S. ve Kumar, S. (2006). "Analytic hierarchy process: An overview of applications". European Journal of Operational Research, 169(1), 1-29.

Laarhoven, P. J. M. ve Pedrycz, W. (1983). “A Fuzzy Extension of Saaty’s Priority Theory”. Fuzzy Sets and Systems, 11(1-3), 199-227.

Wang, Y.-M., Luo, Y. ve Hua, Z. (2008). "On the extent analysis method for fuzzy AHP and its applications". European Journal of Operational Research, 186(2), 735-747.

Whitchurch, C. (2007). "Who do they think they are? The changing identities of professional administrators and managers in UK higher education". Journal of Higher Education Policy and Management, 28(2), 159-171.

Zalesny, M. D. (1985). "Comparison of economic and noneconomic factors in predicting faculty vote preference in a union representation election". Journal of Applied Psychology, 70(2), 243256.

\section{SUMMARY}

In this study, factors effecting the voting decision in a candidate rector election is investigated as a case for manager election processes taking place in higher education institutions. The process towards rector elections in Turkish Public Universities is an important stage where academic faculty need to make a decision based on a variety factors. Until October 2016, rector elections were repeated every four years and it was an important topic on the universities' agenda. 
As in the most developing countries, universities in Turkey undertake important missions in the economic and social development of the country. Rectors positioned at the top of the management have important roles with their authority and responsibilities to shape and realize the prescribed goals of the universities. Very few country uses elections to determine university rectors thus there are no studies available in the literature investigating the voting behavior in these conditions.

In the first stage of the study, factors/criteria effecting the voting decision is determined by a group of experienced faculty members and defined in five headings as; appointment of the candidate by the President (appointment potential); potential number of votes the candidate could receive (vote potential); past managerial performance and future plans of the candidate (performance potential); voter's level of personal relations with the candidate (personal relationship); voter's expected gain in return for his/her vote (expected gain).

In the next stage of the study, the importance of the factors/criteria effecting the voting decisions determined using Fuzzy Analytical Hierarchy Process (FAHP) method with two different approaches: Buckley's FAHP and Csutora and Buckley's FAHP methods. A public university that recently held a rector election is chosen to conduct the study. Out of 589 voter population, a sample of 126 faculty members chosen randomly to participate in the study. Each faculty position represented as equal percentages as in the population (Professor 15\%, Associate Professor 27\%, and Assistant Professor 59\%). Participants were asked to answer a pairwise comparison questioner involving five factors/criteria that may affect their voting behavior. Analysis done for each faculty position separately in order to determine if the effect of the factors/criteria differentiate for each position. The overall results show that both methods achieve the same ranking of the factors/criteria in each analysis. However, the spread of the fuzzy weights calculated using Csutora and Buckley's FAHP method is less than Buckey's FAHP method. Thus Csutora and Buckley's FAHP method is chosen for the comparison of the analysis results. Based on the combined results, factors listed based on their importance as follows; performance potential, personal relationship, appointment potential, vote potential, and expected gain.

Although the ranking of the factors/criteria are the same for all faculty positions, importance levels differ across each position. Performance potential criterion is the most important factor for all the faculty positions. However importance weight (45\%) is the highest for the Associate Professors. Appointment potential criterion is rated higher than the personal relationship criterion by the Assistant Professors compare to the other positions. First three criteria's importance level is very close to each other for the Professor position. According to these results one criterion has a big influence on Associate and Assistant professors' voting decisions. Whereas, three criterion influence Professor's voting decision. This study is a first attempt to understand the voting behaviors of the academic faculty in manager elections of higher education institutions. Further studies are needed in order to generalize these findings. 